\title{
Structural Analysis and Response Surface Optimization of Transport Aircraft Wing
}

\author{
Ahmad Abdul Ghaffar Hanif ${ }^{{ }^{1}}$, Hongshuang Li ${ }^{1}$, Muhammad \\ Kamran', Muhammad Abdullah ${ }^{2}$ \\ ${ }^{* 1}$ College of Aerospace Engineering \\ Nanjing University of Aeronautics and Astronautics, Nanjing 210016, China \\ Email:ahmad@outlook.com,hongshuangli@nuaa.edu.cn \\ ${ }^{2}$ CESAT, Islamabad, Pakistan \\ Email: kamranm470@yahoo.com,abdullah.zafar20@yahoo.com
}

\begin{abstract}
In the design of an aircraft, wing is a very crucial part in order to strengthen it for stable and robust structures. The static structural analysis of a wing is executed via ANSYS (FEA software). The aircraft wing is optimized by varying the thickness keeping in view the desired equivalent maximum stress at different flying conditions. In this proposed work, the modeling of the aircraft wing is carried out incorporating spars and ribs, using CAD software, performing static structural analysis for given loads using computational tools, and then an optimization technique Response Surface Optimization is performed to study the behavior of maximum stress in the aircraft wing.
\end{abstract}

Keywords: Aircraft, Ansys, maximum stress, response surface optimization, structural stability and wing.

\section{Introduction}

The primary function of an aircraft wing is to generate an adequate amount of lift. Two most important components of the aircraft wing are drag and pitching moment. It is endeavored to design the aircraft wing such as the lift is maximized and the drag and pitching moment are minimized. The pressure difference between the upper and lower surface of the aircraft wing produces lift. Hence, the wing is considered as the lifting surface. The specific design of an aircraft wing relies on various features, such as; loads, size and category of aircraft etc. Wing is also sometimes used for fuel 
storage in the aircrafts; it is designed in such a way that the fuel tank is constructed inside the wing. In the aircraft, the right wing and left wing are marked based on the seating of pilot.

Generally, the categorization of stations is carried out in the aviation industry for precisely locating each structural component. Fuselage stations (FS) are numbered from a reference datum. The distance to a given point is measured parallel to a center line from the nose to the tail cone. Normally the nose of aircraft is assigned " 0 " station. Water line (WL) assigns the height perpendicular from a horizontal plane such as ground or floor of the cabin. Butt line or buttock line (BL) is a vertical reference plane from which dimensions on right or left can be noted. A buttock line shows the stations along the vertical plane of the wing as presented in Fig. 1 [1].

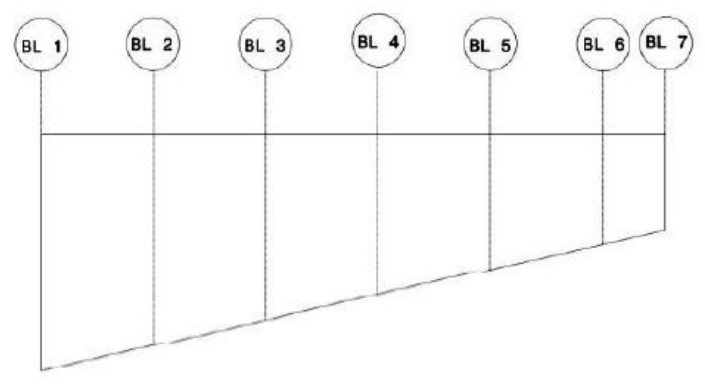

Fig. 1. Presentation of buttock lines on a wing

The construction of aircraft wing usually involves metals and alloys having no peripheral support, like a cantilever design. Mostly, the skin is part of the structure of wing, thus allowing it to bear and carry applied loads and generated stresses on the wing. To strengthen the wing to sustain these loads and stresses; spars, ribs, and stringers are incorporated inside the wing structure. The ribs are placed chord wise whilst the spars are running along the wing span. Spars act as major structural members of the aircraft wing and hence are frequently referred as "beams".

One of the methods used for construction of wing is shown in Fig. 2 [1]. It contains front and rear spars span wise. Ribs are positioned chord wise, which also maintain the airfoil of the wing. Such a construction is referred as "two-spar" or "twin-spar" wing. Spar is a very crucial and vital part of the wing as the bending strength is afforded by it and that is why; mostly spars start inside the fuselage and ends up at the wing tip. During the flight, the load is transmitted from the skin to the ribs. The transferred load is then again redistributed from ribs to the spars. Ribs are categorized as nose ribs, intermediate ribs and trailing edge ribs. Ribs located near the leading edge are referred nose ribs, while the ribs in between both the spars are named 
intermediate ribs and the ribs closer to the trailing edge are identified as trailing edge ribs. The analysis of aircraft wing is a multifaceted, complicated and time intensive procedure. Optimization of wing structure is one way to solve this intricacy which can be effectively abridged by numerical method techniques such as finite element methods.

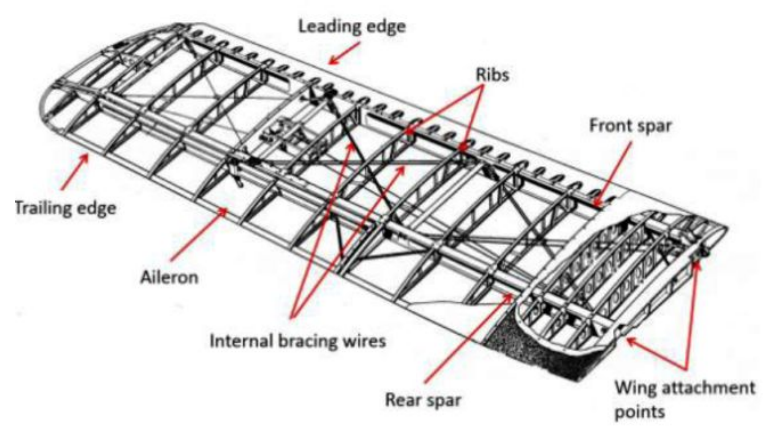

Fig. 2. Construction of wing.

\section{Related Work}

Many researchers have contributed a lot in the field of aircraft wing design. Some of their work is primarily highlighted in the next paragraphs. Sureka and Meher in their study used wing of A300 aircraft alongwith ribs and spars. A300 has standard NACA airfoil 64215. The modeling of wing was carried out in CATIA V5 R20 (CAD software), and analysis on structure of the wing was performed using FEA software (ANSYS Workbench). They found minimum variation in deformation, equivalent shear stress, maximum principle stress and stress intensity among Aluminium (Al) alloy and Al 7068. They concluded that Al 7068 is better than Al alloy in terms of achieving more structural strength [2]. Kavya and Reddy utilized Pro/Engineer, CAD software to model the wing of an aircraft. Their study involved modification of the wing (addition of ribs and spars). Static structural analysis using ANSYS Workbench was carried out on the frame of wing. The outcome of their analysis revealed that stresses and deformation was reduced for modified wing as compared to original wing. Modal analysis showed that deformations were less for new wing (having spars and ribs). Random vibration analysis, also ended up with less shear stress for the proposed new wing. Their conclusion showed that addition of ribs and spars increases the wing strength [3]. In the work of Senthilkumar et.al, modeling of NACA 65210 airfoil for the aircraft wing was performed using standard CAD software, CATIA. They performed dynamic structural analysis using ANSYS Workbench on the frame 
of wing. They studied dynamic structural response of an aircraft wing analyzing two dissimilar models of wing and various material properties. The self-weight of the wing was considered as load condition. The displacements and frequencies for various mode shapes were obtained. Their conclusion resulted that taper wing was superior to the rectangular in terms of the stiffness of the wing [4]. In the work of V. Kumar et.al, the modeling of wing of the aircraft was achieved using CATIA (CAD software). They fixed the appropriate wing structure within the particular flight envelope and calculated the weight at lift-off, maximum stress distribution, wing loading, distance for take-off, vibration modes of less frequency and stall velocity. MSC NASTRAN/ PATRAN package was utilized for the optimization of wing. Their design optimization assured the stability and strength criteria of aircraft wing assuming shell elements for the wing skin, whereas; beam elements for stringer, flange, and spar were considered [5]. Mazhar and Khan carried out the analysis for strength and stiffness of wing of Unmanned Aerial Vehicle (UAV) in ANSYS, FEA software. In their study, they used Artificial Neural Networks approach for application of aerodynamic loads on the structure of wing. For the purpose of deciding the best possible arrangement with, optimized strength and stiffness, minimum weight and cost; the analysis for different material lay-up and variation in geometry were examined. They ended up in a result that wing made up of composite material and two spars were most feasible. Their conclusion was that the wing fabricated with composite material has significant weight reduction as evaluated to the same aluminium wing, and having the same strength to meet all in-flight loads [6].

\section{Methodology}

In our work, we modeled a wing structure using CAD software, the model was analysed for structural analysis in Ansys (FEA software). After obtaining the results from structural analysis, response surface method (RSM) optimization technique was performed. The RSM is a compilation of methods related to mathematics and statistics; helpful in various processes such as improving, developing and optimizing. In the industrial world the use of RSM is very common and efficient. In general, the relationship of a method linking a response $\mathbf{y}$, that involves the input values $\xi_{1}, \xi_{2}, \ldots$ $\xi_{\mathrm{n}}$ is written as follows:

$$
\mathbf{y}=\mathbf{f}\left(\xi_{1}, \xi_{2}, \ldots \xi_{\mathrm{n}}\right)+\boldsymbol{\varepsilon}
$$

whereas response function is $\mathbf{f}$ and the term $\boldsymbol{\varepsilon}$ represents error/ variability (e.g. measurement error, etc. assume that its mean is zero): 


$$
\mathbf{E}(\mathbf{y}) \equiv \eta=\mathbf{E}\left[\mathbf{f}\left(\xi_{1}, \xi_{2}, \ldots \xi_{\mathrm{n}}\right)\right]+\mathbf{E}[\varepsilon]=\mathbf{f}\left(\xi_{1}, \xi_{2}, \ldots \xi_{\mathrm{n}}\right)
$$

Most of the times, it is easier to convert these variables to the dimensionless coded variables $\mathrm{x}_{1}, \mathrm{x}_{2}, \ldots \mathrm{x}_{\mathrm{n}}$. It can be written as

$$
\boldsymbol{\eta}=\mathbf{f}\left(\mathrm{x}_{1}, \mathrm{x}_{2}, \ldots \mathrm{x}_{\mathrm{n}}\right)
$$

f is unknown therefore an approximation is needed. For a small zone of the independent variable space, first or second order (a low-order polynomial) is implemented. The first-order model (in terms of the coded variables) is represented as

$$
\eta=\beta_{0}+\beta_{1} x_{1}+\beta_{2} x_{2}
$$

When there is an interaction between the parameters, the main effects model is used which can be written as

$$
\boldsymbol{\eta}=\boldsymbol{\beta}_{0}+\boldsymbol{\beta}_{1} \mathbf{x}_{1}+\boldsymbol{\beta}_{2} \mathbf{x}_{2}+\boldsymbol{\beta}_{12} \mathbf{x}_{1} \mathbf{x}_{2}
$$

Occasionally the response function is illustrated as the second-order model. The following equation will describe it along with interaction between the variables

$$
\boldsymbol{\eta}=\boldsymbol{\beta}_{0}+\boldsymbol{\beta}_{1} \mathbf{x}_{1}+\boldsymbol{\beta}_{2} \mathbf{x}_{2}+\boldsymbol{\beta}_{1} \mathbf{x}_{12}+\boldsymbol{\beta}_{2} \mathbf{x}_{22}+\boldsymbol{\beta}_{12} \mathbf{x}_{1} \mathbf{x}_{2}
$$

The second-order model is flexible and has the ability for easy estimation of the $\beta$ values [7].

\section{Results and Discussion}

In this study, the twin-spar wing geometry comprises ribs and skin at upper and lower surface of the wing. Structural steel with $3 \mathrm{~mm}$ thickness is selected as the material of the wing. The design of the aircraft wing is a replica of Boeing 767, a twin-aisle commercial aircraft. A supercritical airfoil BACXXX, was selected for this analysis, as used by other researchers too. [8]-[10] The dimensions of this aerofoil were recorded from the UIUC database (University of Illinois at Urbana-Champaign). The normalized dimensions are shown in Fig. 3. [11] The thickness to span chart for upper and lower surface of wing presented in a book by Niu [12] was referred while modeling the wing thickness. The waterline to span for the upper and lower surface of 
the wing is given in Fig. 4. Furthermore, the wing model design calculations are in accordance with the technique, as recommended by Torenbeek. [13]

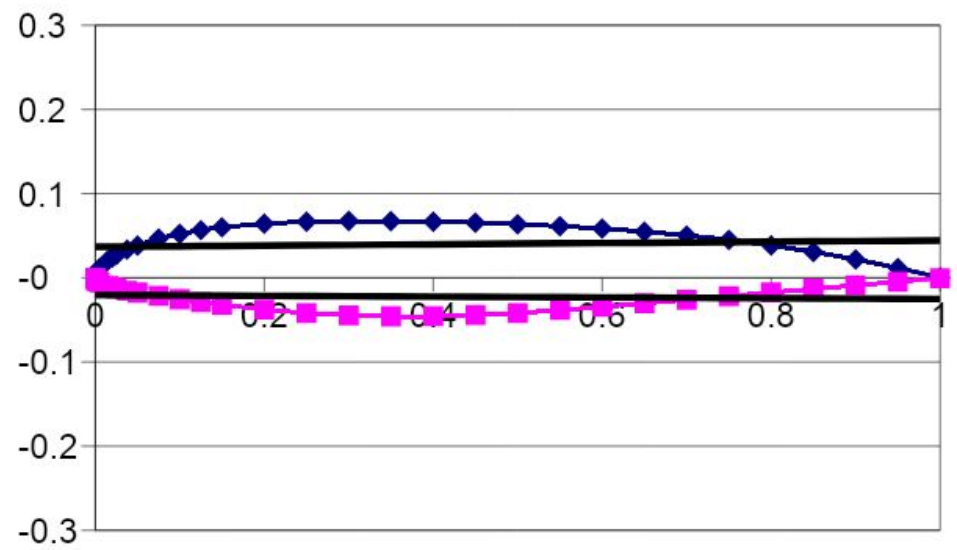

Fig. 3. Supercritical Airfoil BACXXX (Normalized Coordinates).

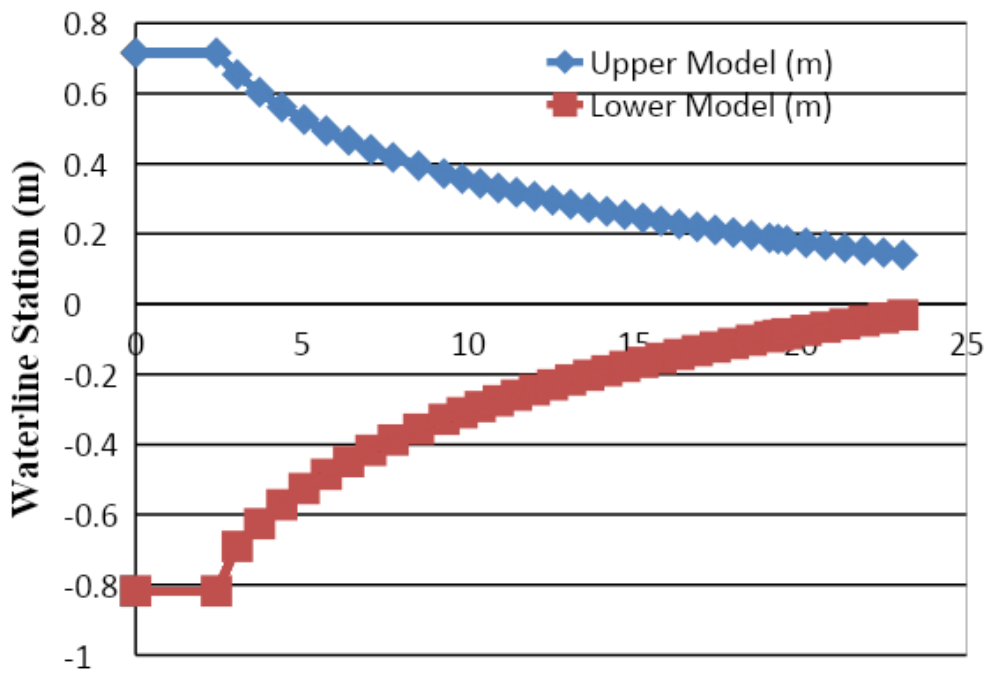

Fig. 4. Waterline to span for the upper and lower surfaces of aircraft wing

The 3D model developed in CAD software is then imported in Ansys 15.0 using the igs file. Then the geometry was "cleaned up" and load conditions were applied. The self-weight of the wing was considered as load (1G-load). The boundary condition as side constraint in the FE model is imposed, thus cantilevering the wing. The meshing was performed using shell elements. In total, there are 3902 shell elements and 10676 nodes. The weight of the current wing model is $6266 \mathrm{~kg}$. The FE model is prepared to 
Gyancity Journal of Engineering and Technology,

Vol.6, No.1, pp. 1-10, January 2020

ISSN: 2456-0065 DOI: 10.21058/gjet.2020.61003

undertake static structural analysis to calculate equivalent maximum stresses and deformation produced as shown in Fig. 5.

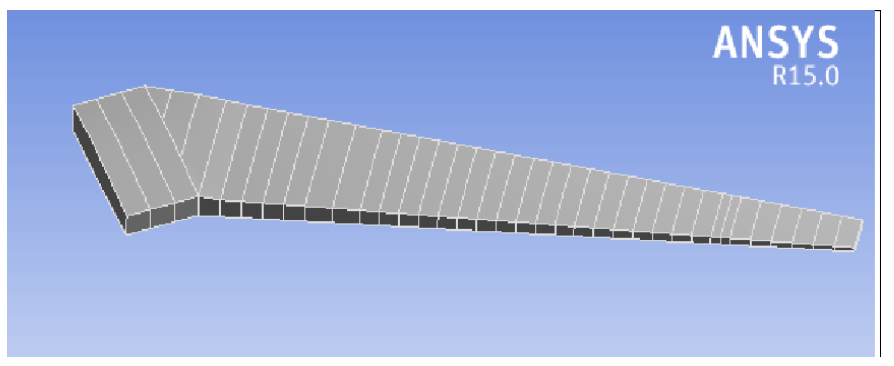

Fig. 5. FE model of wing for static structural analysis

Equivalent stress, equivalent elastic strain and total deformation in the wing were determined using the static structural analysis as shown in Figs. 6, 7 and 8, respectively.

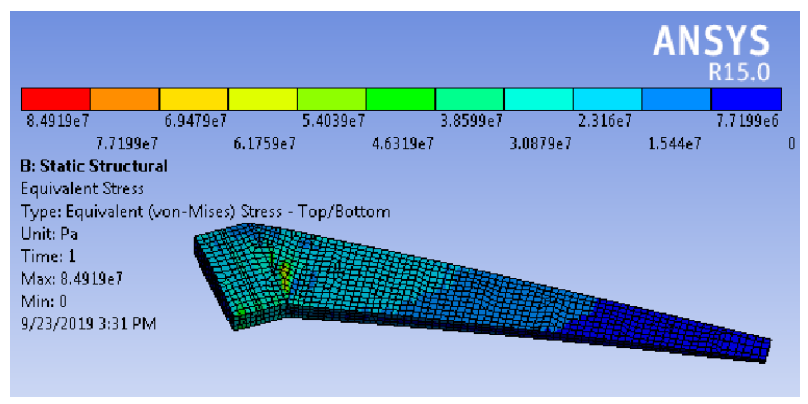

Fig. 6. Equivalent stress in the wing.

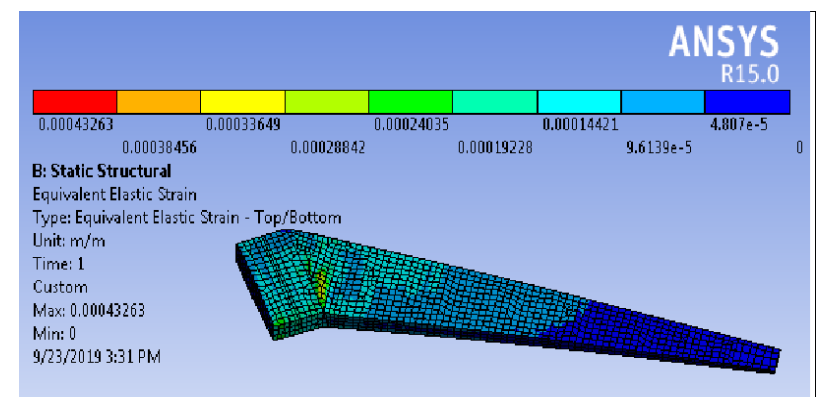

Fig. 7. Equivalent elastic strain in wing.

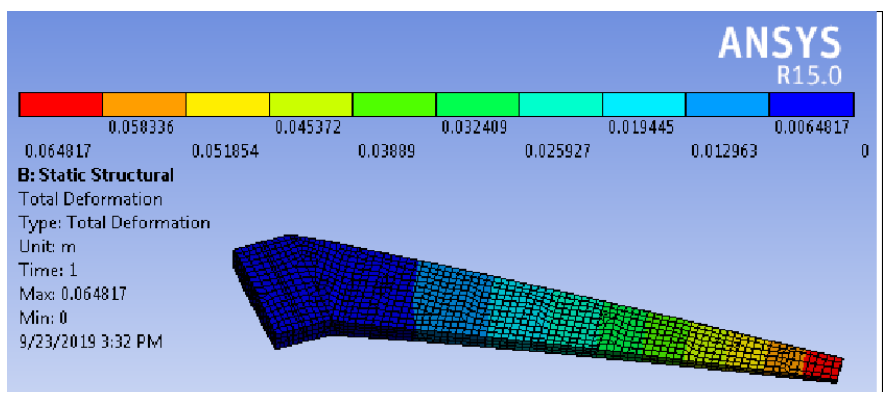

Fig. 8. Total deformation in the wing. 
The optimization of wing is performed using built-in optimization technique in Ansys 15.0 i.e. Response Surface Optimization. The results are presented in Fig. 9. In this technique, the behavior of stress in the wing with regards to thickness was observed. It reveals that the value of stress can be minimized to $8.3397 \times 10^{7} \mathrm{~Pa}$ if we consider the thickness of $3.3 \mathrm{~mm}$ instead of $3 \mathrm{~mm}$. It can be clearly seen that increasing the thickness of the wing yields less stresses as the graph also depicts in Fig. 10.

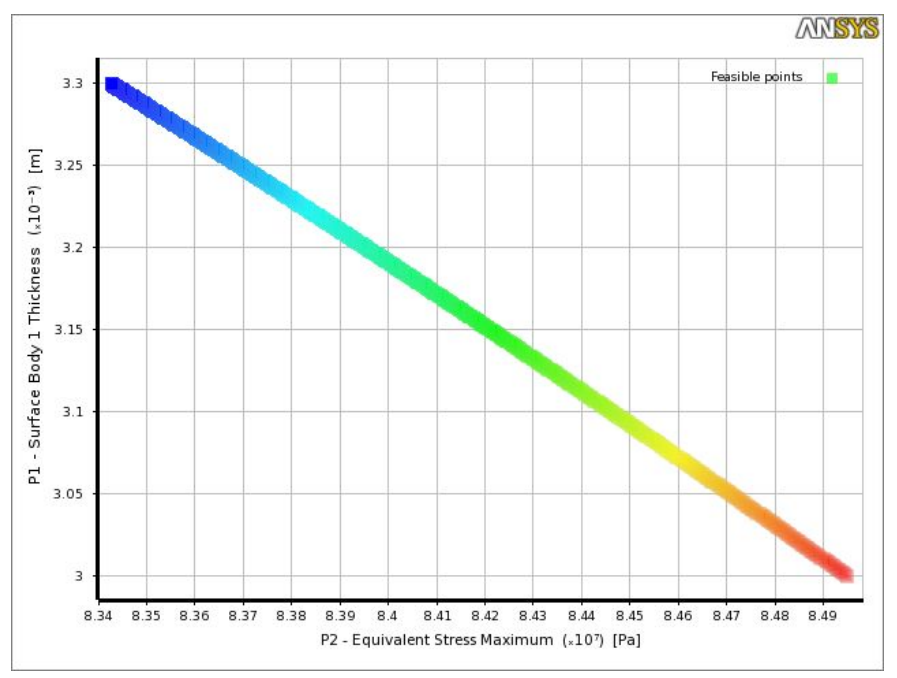

Fig. 9. Trade off chart of response surface optimization.

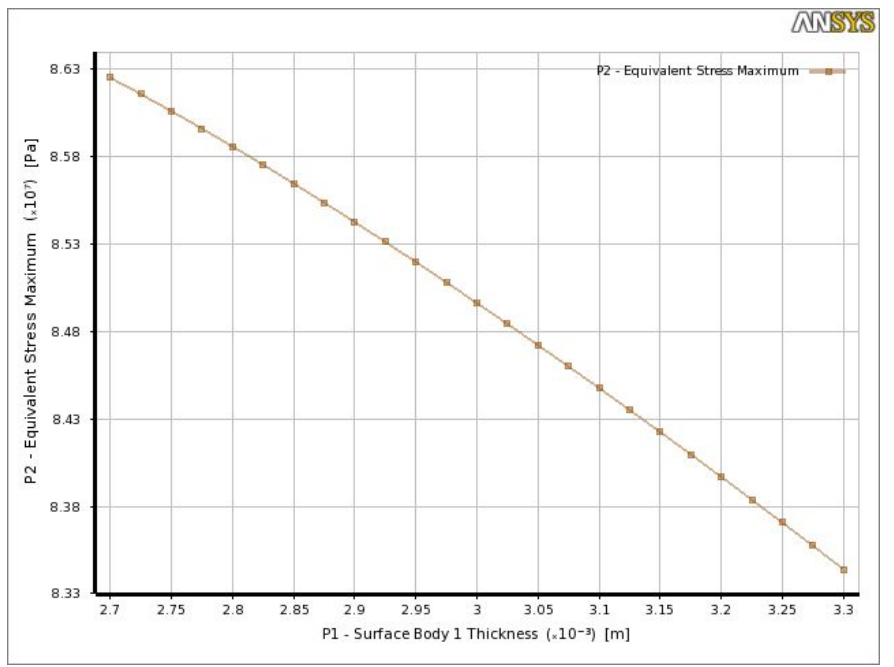

Fig. 10. Equivalent maximum stress w.r.t thickness of wing. 


\section{Conclusion}

In this study, equivalent maximum stress on the wing is analyzed for the optimal thickness of the aircraft wing during the preliminary design process. Response surface optimization method is used to analyze this parameter in order to make the design process; simple, less time consuming and cost effective. Many researchers have incorporated the Computer Aided Design Tools to optimize the wing structure. The computer assisted engineering methods for modeling, analysis and optimization ascertain to be the most commercial, persistent and easy to use process to be implemented by the designers and the researchers to deal with the industrial needs for speedy and rapid design modifications. This work can find a place in conducting and executing static structural analysis of aircraft wing at design stage. Hence, for sturdy and stable structure of aircraft wing the static structural analysis performed is a viable option for finalizing the design parameters in the initial design phase.

\section{References}

[1] ATSB Transport Safety Report [Insert Mode] Occurrence Investigation, AO-2013-226, Final -21 January 2016, Australian Transport Safety Bureau. Microwave Theory \& Tech., vol. 48, no. 12, pp. 2397-2402, December 2000.

[2] K. Sureka and R. S. Meher "Modeling and structural analysis on A300 flight wing by using ANSYS" International Journal of Mechanical Engineering and Robotics Research Vol. 4, No. 2, April 2015.

[3] G. Kavya and B. C. R. Reddy "Design and finite element analysis of aircraft wing using ribs and spars" International Journal and Magazine of Engineering, Technology, Management and Research. Volume No: 2 (2015), Issue No: 11 (November).

[4] S. Senthilkumar, A. Velayudham, and P. Maniarasan "Dynamic structural response of an aircraft wing using Ansys" International Journal of Engineering Research \& Technology (IJERT), Vol. 2 Issue 6, June - 2013.

[5] T. S. V. Kumar, A. W. Basha, M. Pavithra, and V. Srilekha "Static and dynamic analysis of a typical aircraft wing structure using MSC Nastran" International Journal of Research in Aeronautical and Mechanical Engineering, Volume: 3 Issue 8, August 2008.

[6] F. Mazhar and A. M. Khan "Structural design of a UAV wing using finite element method" $51^{s t}$ AIAA/ASME/ ASCE/AHS/ASC Structures, Structural Dynamics, and Materials Conference $<$ BR $>18$ th 12 - 15 April 2010, Orlando, Florida.

[7] R. H. Myers, D. C. Montgomery, C. M. Anderson, Cook "Response surface methodology Process and Product Optimization Using Designed Experiments". $3^{\text {rd }}$ edition, 2009, Wiley.

[8] D. A. Brown, “Advanced Airfoils Studied for Transports", Aviation Week and Space Technology, Vol. 92, No. 25, June 22, 1970, pp.55-57;60.

[9] D. Anderson, "Dateline America: supercritical wing", Flight, Vol. 100, No. 3251, July 1, 1971, pp. 23-26. 
[10]R. G. Albers, M. E. Tuttle and W. B. Avery, "Subsonic Transport Composite Wing Model for Optimization Studies", Proceedings of the 12th AIAA/ISSMO Multidisciplinary Analysis and Optimization Conference, Victoria, British Columbia, Canada, AIAA, Reston, VA, September 10-12, 2008, AIAA-2008-6016.

[11]Seligh, M, UIUC Airfoil Coordinates Database, Version 2.0, URL: http://www.ae.uiuc.edu/m-seligh/ads/coord_database.html -B, Nov. 11,2005.

[12]M. C.-Y. Niu, Airframe Structural Design: Practical Design Information and Data on Aircraft Structures, Conmilit Press Ltd., Hong Kong, 1988 C

[13]E. Torenbeek, "Development and application of a comprehensive, design-sensitive weight prediction method for wing structures for transport category aircraft", Delft University of Technology, Report LR-693, Delft, The Netherlands, Sep., 1992. 